\title{
Defining Essential Topics and Procedures for Korean Family Medicine Residency Training
}

\author{
Youhyun Song', Jinyoung Shin², Yonghwan Kim³, Jae-Yong Shim ${ }^{4, *}$ \\ 'Department of Family Medicine, Gangnam Severance Hospital, Yonsei University College of Medicine, Seoul, Korea \\ ${ }^{2}$ Department of Family Medicine, Konkuk University Medical Center, Konkuk University School of Medicine, Seoul, Korea \\ ${ }^{3}$ Department of Family Medicine, Chungbuk National University Hospital, Cheongju, Korea \\ ${ }^{4}$ Department of Family Medicine, Severance Hospital, Yonsei University College of Medicine, Seoul, Korea
}

Background: This study aims to create a comprehensive list of essential topics and procedural skills for family medicine residency training in Korea.

Methods: Three e-mailed surveys were conducted. The first and second surveys were sent to all board-certified family physicians in the Korean Academy of Family Medicine (KAFM) database via e-mail. Participants were asked to rate each of the topics (117 in survey 1, 36 in survey 2) and procedures (65 in survey 1, 19 in survey 2) based on how necessary it was to teach it and personal experience of utilizing it in clinical practice. Agreement rates of the responses were calculated and then sent to the 32 KAFM board members in survey 3 . Opinions on potential cut-off points to divide the items into three categories and the minimum achievement requirements needed to graduate for each category were solicited.

Results: Of 6,588 physicians, 256 responded to the first survey (3.89\% response rate), 209 out of 6,669 to the second survey $(3.13 \%)$, and $100 \%$ responded to the third survey. The final list included 153 topics and 81 procedures, which were organized into three categories: mandatory, recommended, and optional (112/38/3, 27/33/21). For each category of topics and procedures, the minimum requirement for 3-year residency training was set at $90 \% / 60 \% / 30 \%$ and $80 \% / 60 \% / 30 \%$, respectively.

Conclusion: This national survey was the first investigation to define essential topics and procedures for residency training in Korean family medicine. The lists obtained represent the opinions of Korean family physicians and are expected to aid in the improvement of family medicine training programs in the new competency-based curriculum.

Keywords: Internship and Residency; Education; Curriculum; Topic; Procedure; Family Medicine

Received: November 9, 2020, Revised: April 23, 2021, Accepted: May 7, 2021

*Corresponding Author: Jae-Yong Shim https://orcid.org/0000-0002-9561-9230

Tel: +82-2-2019-2630, Fax: +82-2-3462-8209, E-mail: hope@yuhs.ac 


\section{INTRODUCTION}

Family medicine, or general practice as described in some countries, by definition, requires a wide, comprehensive range of medical knowledge and the ability to perform diverse clinical procedures. As such, even with the 2005 Korean Academy of Family Medicine (KAFM) residency curriculum under implementation, individual family medicine residency training programs vary widely. In part, this may have to do with the 2005 curriculum being too vast and inclusive. To ensure the quality of nextgeneration family physicians, especially with the new labor laws restricting resident hours to less than 80 hours a week, it is becoming increasingly important to define "essential" or "core" topics and procedures.

Lists of core topics or procedural skills for family medicine residency training programs have been created in several countries by varying methods with diverse outcomes. ${ }^{1-6)}$ In the case of procedural skills, for instance, in Canada, an initial survey of all residency program directors of family medicine produced 24 lists with the number of skills varying from 10 to $75 .{ }^{7)}$ The currently used versions of the lists of priority topics and core procedures are much more comprehensive and will be described later. The United States also initially surveyed all program directors and obtained 63 lists of procedures with varying numbers of skills (3-117) ${ }^{8)}$ Currently, two lists of procedural skills (required and advanced) are in circulation, and the Residency Curriculum Resources Project is under progress for the selection of topics. ${ }^{9,10)}$ The Royal College of General Practitioners also had a list of mandatory procedural skills, although recent changes discarded the specific list and now it requires five mandatory exams with others that are not specified. ${ }^{11)}$

The KAFM, through the Section of the Residency Training Committee, commissioned the Working Group in 2018. This paper describes the process followed by the Working Group for developing a refined list of topics and procedures specifically for training family medicine doctors in Korea.

\section{METHODS}

This study was conducted using three Internet surveys. The first and second surveys utilized Google Forms and were sent to all board-certified family physicians in the KAFM e-mail database. The third survey was sent to board members of the KAFM via conventional e-mail correspondence. This study was approved by the Institutional Review Board of Severance Hospital (approval no., 4-2020-0969). Informed consent was waived.

\section{First Survey}

Participants were given lists of the Canadian 99 priority topics, 65 core procedures, and 18 topics from the 2005 KAFM residency curriculum. They were asked to rate each topic or procedure according to the following two statements: (1) Statement 1: "I would expect a graduate of a 3-year family medicine program in Korea to have learned this topic or procedure." (2) Statement 2: "I have personally experienced utilization of knowledge of this topic or performed this procedure after resi- dency training."

The answer options for statement 1 were "agree," "neutral," and "disagree." The options for statement 2 were "yes" and "no." Participants were additionally asked to add any topics or procedures that they thought should be covered in residency training.

\section{Second Survey}

All participants were given a list of 36 topics and 19 procedural skills that were newly produced from the first survey. They were asked to rate each topic and procedure in the same manner as in the first survey.

\section{Third Survey}

The KAFM board members were given a compiled list of 153 topics and 84 procedures gathered from surveys 1 and 2 . All topics and procedures were presented as percentages of positive responses from high to low for statements 1 (need) and 2 (used), respectively. For statement 1, we included the rating "neutral" as "agree" in the calculation. Participants were asked to fill in percentages in the blanks in the following statements and reply by e-mail.

(1) I think topics with a "used" percentage above ( )\% or "need" percentage above ( )\% should be classified as "mandatory," and at least ( )\% of the "mandatory" topics should be covered in a 3-year residency training program.

(2) I think topics with "used" percentage above ( )\% or "need" percentage above ( )\% should be classified as "recommended," and at least ( )\% of the "recommended" topics should be covered in a 3 -year residency training program.

(3) I think topics with "used" percentage above ( )\% or "need" percentage above ( )\% should be classified as "optional," and at least ( )\% of the "optional" topics should be covered in a 3-year residency training program.

The same statements were also presented for procedures.

Table 1. Baseline characteristics of participants

\begin{tabular}{lcc}
\hline \multicolumn{1}{c}{ Characteristic } & First survey $(\mathrm{n}=256)$ & Second survey $(\mathrm{n}=209)$ \\
\hline Gender & & \\
Female & $107(41.8)$ & $75(36.4)$ \\
Male & $149(58.2)$ & $131(63.6)$ \\
Area & & \\
Capital region & $145(56.7)$ & $100(48.5)$ \\
Non-capital region & $111(43.3)$ & $109(51.5)$ \\
Status & & \\
Academic & $142(55.5)$ & $88(42.7)$ \\
Non-academic & $114(44.5)$ & $121(57.3)$ \\
Years in practice & & \\
$0-5$ & $90(35.1)$ & $74(35.9)$ \\
$5-10$ & $66(25.8)$ & $47(22.8)$ \\
$10-15$ & $43(16.8)$ & $36(17.5)$ \\
$15-20$ & $22(8.6)$ & $19(9.2)$ \\
$>20$ & $35(13.7)$ & $30(14.6)$ \\
\hline
\end{tabular}

Values are presented as number (\%). 
Table 2. 153 Essential topics for family medicine residency training derived by family physician survey

\begin{tabular}{|c|c|}
\hline Variable & 153 Essential topics \\
\hline \multicolumn{2}{|c|}{112 Mandatory topics } \\
\hline 1 & Advanced cardiac life support \\
\hline 2 & Chronic obstructive pulmonary disease \\
\hline 3 & Electrocardiogram interpretation \\
\hline 4 & Research in family medicine \\
\hline 5 & Family issues \\
\hline 6 & Family-centered care \\
\hline 7 & Hepatitis \\
\hline 8 & Infections \\
\hline 9 & Thyroid disorders \\
\hline 10 & Health supplements \\
\hline 11 & Conjunctivitis \\
\hline 12 & Tuberculosis \\
\hline 13 & Hyperlipidemia \\
\hline 14 & Hypertension \\
\hline 15 & Osteoporosis \\
\hline 16 & Fractures \\
\hline 17 & Joint disorders \\
\hline 18 & Education (patient/physician) \\
\hline 19 & Earache \\
\hline 20 & Evidence-based medicine \\
\hline 21 & Smoking cessation \\
\hline 22 & Cough \\
\hline 23 & Other endocrinology \\
\hline 24 & Other rheumatology (e.g., gout) \\
\hline 25 & Other cardiology \\
\hline 26 & Other ear, nose, and throat conditions \\
\hline 27 & Other pulmonology \\
\hline 28 & Bad news \\
\hline 29 & Elderly \\
\hline 30 & Aging \\
\hline 31 & Stroke \\
\hline 32 & Gallbladder polyp \\
\hline 33 & Cholecystitis \\
\hline 34 & Gallbladder stones \\
\hline 35 & Diabetes \\
\hline 36 & Difficult patient \\
\hline 37 & Headache \\
\hline 38 & Chronic disease \\
\hline 39 & Neck pain \\
\hline 40 & Substance abuse (including alcohol) \\
\hline 41 & Fever \\
\hline 42 & Dysuria \\
\hline 43 & Abdominal pain \\
\hline 44 & Multiple medical problems \\
\hline 45 & Sinusitis \\
\hline 46 & Arrhythmia \\
\hline 47 & Insomnia \\
\hline 48 & Anxiety \\
\hline 49 & Obesity \\
\hline 50 & Rhinitis \\
\hline 51 & Epistaxis \\
\hline 52 & Anemia \\
\hline 53 & Upper respiratory infection \\
\hline 54 & Lifestyle \\
\hline 55 & Diarrhea \\
\hline 56 & Sexually transmitted infections \\
\hline
\end{tabular}

(Continued on next page)
Table 2. Continued

\begin{tabular}{|c|c|}
\hline Variable & 153 Essential topics \\
\hline 57 & Children and adolescents \\
\hline 58 & Dyspepsia \\
\hline 59 & Stress \\
\hline 60 & Somatization \\
\hline 61 & Atrial fibrillation \\
\hline 62 & Heart failure \\
\hline 63 & Red eye \\
\hline 64 & Dry eye \\
\hline 65 & Allergy \\
\hline 66 & $\begin{array}{l}\text { Cancer; overview (including initial diagnosis } \\
\text { and evaluation, family counselling) }\end{array}$ \\
\hline 67 & Grief \\
\hline 68 & Pharmacology (including polypharmacy) \\
\hline 69 & Dizziness \\
\hline 70 & Travel medicine \\
\hline 71 & Gastroesophageal reflux disease \\
\hline 72 & Lacerations \\
\hline 73 & $\begin{array}{l}\text { Diagnostic imaging (ultrasound, computed } \\
\text { tomography, X-ray, etc.) }\end{array}$ \\
\hline 74 & Intravenous nutrition therapy \\
\hline 75 & Nutrition \\
\hline 76 & Immunization \\
\hline 77 & Urinary tract infection \\
\hline 78 & Low-back pain \\
\hline 79 & Depression \\
\hline 80 & Exercise \\
\hline 81 & Gastritis/peptic ulcer disease \\
\hline 82 & Gastrointestinal bleed \\
\hline 83 & Breast lump \\
\hline 84 & Medical ethics \\
\hline 85 & Mental competency \\
\hline 86 & Loss of consciousness \\
\hline 87 & Private clinic administration \\
\hline 88 & Tinnitus \\
\hline 89 & Prostate disorders \\
\hline 90 & Periodic health assessment/screening \\
\hline 91 & Counselling \\
\hline 92 & Otitis media \\
\hline 93 & Disease prevention and health promotion \\
\hline 94 & Vaginitis \\
\hline 95 & Asthma \\
\hline 96 & Weight loss \\
\hline 97 & Dementia \\
\hline 98 & Hemorrhoids \\
\hline 99 & Croup \\
\hline 100 & Alopecia \\
\hline 101 & Dehydration \\
\hline 102 & $\begin{array}{l}\text { Pain medicine (trigger point injection, block, } \\
\text { medication, etc.) }\end{array}$ \\
\hline 103 & Menopause \\
\hline 104 & Pneumonia \\
\hline 105 & Fatigue \\
\hline 106 & Skin disorders \\
\hline 107 & Contraception \\
\hline 108 & Antibiotics \\
\hline 109 & Ischemic heart disease \\
\hline 110 & Palliative care \\
\hline 111 & $\begin{array}{l}\text { Medical interview skills and the doctor-patient } \\
\text { relationship }\end{array}$ \\
\hline
\end{tabular}

(Continued on next page) 
Table 2. Continued

\begin{tabular}{|c|c|}
\hline Variable & 153 Essential topics \\
\hline 112 & Chest pain \\
\hline \multicolumn{2}{|c|}{38 Recommended topics } \\
\hline 1 & Obstructive sleep apnea \\
\hline 2 & Domestic violence \\
\hline 3 & Well-baby care \\
\hline 4 & Seizures \\
\hline 5 & Oral health maintenance \\
\hline 6 & Sarcopenia \\
\hline 7 & Violent/aggressive patient \\
\hline 8 & Glaucoma \\
\hline 9 & Meningitis \\
\hline 10 & Lacrimal disorder \\
\hline 11 & Manual therapy \\
\hline 12 & Poisoning \\
\hline 13 & Homecare medicine \\
\hline 14 & Cataract \\
\hline 15 & Complementary alternative medicine \\
\hline 16 & Adrenal insufficiency \\
\hline 17 & Infertility \\
\hline 18 & Eating disorders \\
\hline 19 & Gender-specific issues \\
\hline 20 & Sex \\
\hline 21 & Rape/sexual assault \\
\hline 22 & Care of the surgical patient \\
\hline 23 & Disability \\
\hline 24 & Deep venous thrombosis \\
\hline 25 & Trauma \\
\hline 26 & $\begin{array}{l}\text { Healthcare-related legislation and policy } \\
\text { (including health insurance bills) }\end{array}$ \\
\hline 27 & Immigrants \\
\hline 28 & Personality disorder \\
\hline 29 & Pregnancy \\
\hline 30 & Suicide \\
\hline 31 & Crisis \\
\hline 32 & Schizophrenia \\
\hline 33 & Community care \\
\hline 34 & Vaginal bleeding \\
\hline 35 & Parkinsonism \\
\hline 36 & Cosmetic dermatology \\
\hline 37 & Behavioral disorders \\
\hline 38 & $\begin{array}{l}\text { Other hemato-oncology including basic concepts } \\
\text { on major malignancies and treatment }\end{array}$ \\
\hline \multicolumn{2}{|l|}{3 Optional topics } \\
\hline 1 & Retinal disorders \\
\hline 2 & Newborns \\
\hline 3 & $\begin{array}{l}\text { Current issues in medicine (e.g., machine } \\
\text { learning, genomics) }\end{array}$ \\
\hline
\end{tabular}

\section{RESULTS}

Regarding response rates, 256 physicians out of 6,588 responded to the first survey (3.89\% response rate) and 209 out of 6,669 to the second survey ( $3.13 \%$ response rate). (Updates to the e-mail database of KAFM explain the number discrepancy.) All 32 board members responded to the third survey. The baseline characteristics of the participants in the first and second surveys are shown in Table 1.
A total of 153 topics and 84 procedures were identified in the first and second surveys. Three procedures were deleted after the third survey; two due to minimal agreement (endometrial aspiration biopsy and artificial rupture of membranes) and one due to possible redundancy, resulting in a final total of 81 . The majority of topics were observed to be both considered essential and utilized in practice, with the exception of 19 topics that were thought needed but not personally used (advanced cardiac life support, croup, domestic violence, immigrant health, infertility, newborns, poisoning, rape/sexual assault, schizophrenia, seizures, suicide, care of the surgical patient, homecare medicine, current issues in medicine, lacrimal disorder, retinal disorder, glaucoma, cataract, and manual therapy). In contrast, less than half of the procedures $(\mathrm{n}=35)$ were evaluated as both performed and needed.

We categorized the topics and procedures into three groups based on responses to the e-mail surveys: "mandatory," "recommended," and "optional." A total of 112 mandatory topics were defined by the response percentile of above either $70 \%$ for "used" or $80 \%$ for "need," and minimum requirement of achievement was set at $90 \%$. The minimum achievement requirements for the 38 recommended topics (40\%-70\% use or 50\%-80\% need) and three optional topics (30\%-40\% use or $40 \%-50 \%$ need) were set at $50 \%$ and $30 \%$, respectively (Table 2 ).

The 27 mandatory procedures were defined by the response percentile of above either $60 \%$ for "used" or $80 \%$ for "need," and minimum requirement of achievement was set at $80 \%$. The minimum achievement requirements for the 33 recommended procedures (40\%-60\% use or $60 \%-80 \%$ need) and 21 optional procedures (20\%-40\% use or $30 \%-60 \%$ need) were set at $60 \%$ and $30 \%$, respectively (Table 3 ).

\section{DISCUSSION}

It comes as no surprise that early attempts at defining "essential" or "core" lists of topics and procedures produced widely varying results domestically, as have the final versions differed largely between countries. In the aforementioned surveys, only 30 procedural skills were common in more than half of the propositioned lists in Canada ${ }^{7)}$ and 25 in the United States. ${ }^{8)}$ Practice location has been reported to influence clinical performance; for example, more skills are utilized more often in rural areas compared to urban regions. Clinical settings, such as training versus non-training hospitals or different tiers of healthcare facilities, would also be significant influencing factors, just to name a few..$^{12,13)}$

There is no "correct answer" when it comes to defining essential topics and procedures; cultural differences with related lifestyle factors create different needs in different nations. Even within one country, "common" clinical issues and frequently applied medical skills are varied, as are community needs. Cost effectiveness is another factor to be considered, as well as the limited timeline available for residency training, which changes with the times.

Thus, it is not surprising that vast differences exist in the methodologies and participant demographics of previously developed "lists" between countries. For example, Canada, a front-runner in the field, even had different processes for selecting topics and procedures. For 
Table 3. 81 Essential procedures for family medicine residency training derived by family physician survey

\begin{tabular}{|c|c|}
\hline Variable & 81 Essential procedures \\
\hline \multicolumn{2}{|c|}{27 Mandatory procedures* } \\
\hline 1 & Esophagogastroduodenoscopy \\
\hline 2 & Musculoskeletal joint exam \\
\hline 3 & Neurologic exam \\
\hline 4 & Oral airway insertion \\
\hline 5 & Wound care (burn, dressing...) \\
\hline 6 & Infiltration of local anesthetic \\
\hline 7 & Removal of foreign body in ear \\
\hline 8 & Removal of cerumen \\
\hline 9 & Intramuscular injection \\
\hline 10 & Endotracheal intubation \\
\hline 11 & Abscess incision and drainage \\
\hline 12 & Fecal occult blood testing \\
\hline 13 & Placement of transurethral catheter \\
\hline 14 & Peripheral intravenous line \\
\hline 15 & Bag-and-mask ventilation \\
\hline 16 & Laceration repair; sutures and adhesives, etc. \\
\hline 17 & Removal of foreign body in nose \\
\hline 18 & Nasogastric tube insertion \\
\hline 19 & Application of sling-upper extremity \\
\hline 20 & Otoscopy \\
\hline 21 & Removal of foreign body \\
\hline 22 & Splinting of injured extremities \\
\hline 23 & Pap smear \\
\hline 24 & Venipuncture \\
\hline 25 & Cardiac defibrillation \\
\hline 26 & Intradermal injection \\
\hline 27 & Subcutaneous injection \\
\hline \multicolumn{2}{|c|}{33 Recommended procedures } \\
\hline 1 & Allergy skin test \\
\hline 2 & Antibiotics skin test \\
\hline 3 & Cardioversion \\
\hline 4 & Central venous catheter insertion \\
\hline 5 & Colonoscopy \\
\hline 6 & Epley maneuver \\
\hline 7 & Paracentesis \\
\hline 8 & Trigger point injection, intramuscular stimulation \\
\hline 9 & Wedge excision for ingrown toenail \\
\hline 10 & Pare skin callus \\
\hline 11 & Drainage acute paronychia \\
\hline 12 & Peripheral venous access-infant \\
\hline 13 & Aspiration/injection, knee joint \\
\hline 14 & Application of below-knee cast \\
\hline 15 & Partial toenail removal \\
\hline 16 & Wound debridement \\
\hline 17 & Adult lumbar puncture \\
\hline 18 & Reduction of dislocated finger \\
\hline 19 & Digital block in finger or toe \\
\hline 20 & Application of eye patch \\
\hline 21 & Aspiration/injection, shoulder joint \\
\hline 22 & Reduce dislocated shoulder \\
\hline 23 & Lateral epicondyle injection; tennis elbow \\
\hline 24 & Application of ulnar gutter splint \\
\hline 25 & Use of Wood's lamp \\
\hline 26 & Anterior nasal packing \\
\hline 27 & Application of forearm cast \\
\hline 28 & Release subungual hematoma \\
\hline
\end{tabular}

(Continued on next page)
Table 3. Continued

\begin{tabular}{|c|c|}
\hline Variable & 81 Essential procedures \\
\hline 29 & Reduce dislocated radial head; pulled elbow \\
\hline 30 & Application of scaphoid cast \\
\hline 31 & Skin scraping for fungus determination \\
\hline 32 & Anoscopy/proctoscopy \\
\hline 33 & $\begin{array}{l}\text { Aspiration and injection of bursae; such as } \\
\text { patellar, subacromial }\end{array}$ \\
\hline \multicolumn{2}{|c|}{21 Optional procedures } \\
\hline 1 & $\begin{array}{l}\text { Biopsy (fine-needle aspiration biopsy, } \\
\text { ultrasound-guided core needle biopsy) }\end{array}$ \\
\hline 2 & Chest tube insertion \\
\hline 3 & $\mathrm{CO}_{2}$ laser \\
\hline 4 & Diaphragm fitting and insertion \\
\hline 5 & Prolotherapy \\
\hline 6 & Thoracentesis \\
\hline 7 & Ventilator care \\
\hline 8 & Removal of corneal or conjunctival foreign body \\
\hline 9 & Cryotherapy or chemical therapy genital warts \\
\hline 10 & Slit lamp examination \\
\hline 11 & Aspirate breast cyst \\
\hline 12 & Insertion of intrauterine device \\
\hline 13 & Cautery for anterior epistaxis \\
\hline 14 & Normal vaginal delivery \\
\hline 15 & Instillation of fluorescein \\
\hline 16 & $\begin{array}{l}\text { Excision of dermal lesions; e.g., papilloma, } \\
\text { nevus, cyst }\end{array}$ \\
\hline 17 & Cryotherapy of skin lesions \\
\hline 18 & Electrocautery of skin lesions \\
\hline 19 & Skin biopsy; shave, punch, excisional \\
\hline 20 & Incision/drain thrombosed external hemorrhoid \\
\hline 21 & Episiotomy and repair \\
\hline
\end{tabular}

*Insertion of sutures was deleted due to possible redundance.

topics, a postal survey of write-in answers was sent to randomly selected 302 examiners in the certification examination of the College of Family Physicians of Canada; the response rate was $54 \%(n=163)$, and no demographic data were collected. ${ }^{1)}$ In selecting procedures, the Delphi technique was employed, with randomly chosen physicians asked to fill surveys to rate the procedures. Participants were evenly recruited from academic, urban, small town, and rural groups, and the total number of participants was $24 .^{7)}$ In the United States, an initial 2001 procedural survey was conducted with 326 residency program directors out of $467 ;^{8)}$ the current consensus was developed by a subset of The Society of Teachers of Family Medicine Group on Hospital Medicine and Procedural Training consisting of 17 family physician educators with varied backgrounds and locations. ${ }^{9)}$

In our study, we were able to collect opinions from a diverse population of family physicians to form a consensus based on educational necessity and clinical utility specific to the current medical environment in Korea. This is the first attempt to define a set of essential clinical topics and procedural skills for family medicine residency training in Korea using opinions from physicians in various settings, representing the general family physicians of Korea. Our findings, similar to those of other studies, showed that educational expectations were 
much higher than actual personal performance. ${ }^{1)}$

There were some limitations in the development of the core lists. The biggest would be the relatively low response rates of the surveys, which could lessen the generalizability of the findings across the diversity of family medicine doctors throughout the nation. Availability of detailed demographic information of all 9,824 KAFM members (as of 2021 ) is limited due to restrictions on accessing personal information. However, gender composition and academic status is in the public domain. The majority of members $(95.2 \%)$ have non-academic status, which shows discrepancy of approximately $50 \%$ with our survey responders. Second, collecting self-reported data, which was unavoidable due to the nature of the surveys, may have influenced the responses. Third, the pool of participants may be slightly biased; it can be deduced that the responses were submitted by individuals more interested in residency training than others.

However, our study has several strengths, such as the similar percentage of participation from the non-academic and academic sectors in the first and second surveys, which (had it been predominantly from academic participants) could otherwise may have led to very skewed results. Moreover, gender composition (40.0\% female and $60.0 \%$ male) of all KAFM members is very similar to the composition of our first and second survey responders. The wide distribution of years in practice (new to over 20 years) also should help in identifying the needs of both young and new-generation doctors as well as benefiting from the time-proven wisdom of the old and experienced generation. Additionally, family medicine practitioners from various regions across the country, including metropolitan cities and rural provinces, participated in the survey from all tiers of healthcare facilities.

When commencing this investigation, the Working Group envisioned these lists to serve as a means of assessment or blueprint for residency training programs, especially with the upcoming transition to a novel competency-based educational curriculum for family medicine. In particular, the aim was to potentially help clarify the broad "mandatory (key) features" within the KAFM's 15 entrustable professional activities; modifications and adjustments are ongoing to refine the lists for application.

In conclusion, the Working Group defined core lists of clinical topics and procedural skills for Korean family medicine residency training for the first time. The lists were derived based on the broadly agreeing opinions of diverse family medicine physicians across the nation belonging to a variety of clinical settings. Future application of these findings is expected to aid in effectively ensuring quality education in residency training and forming guidelines for training program evaluation. It is important to conduct further research, building on this preliminary study, to improve and refine the list.

\section{CONFLICT OF INTEREST}

No potential conflict of interest relevant to this article was reported.

\section{ORCID}

Youhyun Song: https://orcid.org/0000-0001-5621-2107

Jinyoung Shin: https://orcid.org/0000-0001-9558-1853

Yonghwan Kim: https://orcid.org/0000-0002-9965-675X

Jae-Yong Shim: https://orcid.org/0000-0002-9561-9230

\section{REFERENCES}

1. Allen T, Brailovsky C, Rainsberry P, Lawrence K, Crichton T, Carpentier MP, et al. Defining competency-based evaluation objectives in family medicine: dimensions of competence and priority topics for assessment. Can Fam Physician 2011;57:e331-40.

2. Baglia J, Foster E, Dostal J, Keister D, Biery N, Larson D. Generating developmentally appropriate competency assessment at a family medicine residency. Fam Med 2011;43:90-8.

3. Tandeter H, Carelli F, Timonen M, Javashvili G, Basak O, Wilm S, et al. A 'minimal core curriculum' for family medicine in undergraduate medical education: a European Delphi survey among EURACT representatives. Eur J Gen Pract 2011;17:217-20.

4. Shaughnessy AF, Sparks J, Cohen-Osher M, Goodell KH, Sawin GL, Gravel J Jr. Entrustable professional activities in family medicine. J Grad Med Educ 2013;5:112-8.

5. Schultz K, Griffiths J, Lacasse M. The application of entrustable professional activities to inform competency decisions in a family medicine residency program. Acad Med 2015;90:888-97.

6. Michels NRM, Maagaard R, Buchanan J, Scherpbier N. Educational training requirements for general practice/family medicine specialty training: recommendations for trainees, trainers and training institutions. Educ Prim Care 2018;29:322-6.

7. Wetmore SJ, Rivet C, Tepper J, Tatemichi S, Donoff M, Rainsberry P. Defining core procedure skills for Canadian family medicine training. Can Fam Physician 2005;51:1364-5.

8. Tenore JL, Sharp LK, Lipsky MS. A national survey of procedural skill requirements in family practice residency programs. Fam Med 2001; 33:28-38.

9. Nothnagle M, Sicilia JM, Forman S, Fish J, Ellert W, Gebhard R, et al. Required procedural training in family medicine residency: a consensus statement. Fam Med 2008;40:248-52.

10. Kelly BF, Sicilia JM, Forman S, Ellert W, Nothnagle M. Advanced procedural training in family medicine: a group consensus statement. Fam Med 2009;41:398-404.

11. Riley B, Haynes J, Field S. The condensed curriculum guide : for GP training and the new MRCGP. London: Royal College of General Practitioners; 2007.

12. Smith MA, Klinkman MS. The future of procedural training in family practice residency programs: look before you LEEP. Fam Med 1995;27: 535-8.

13. Wickstrom GC, Kelley DK, Keyserling TC, Kolar MM, Dixon JG, Xie SX, et al. Confidence of academic general internists and family physicians to teach ambulatory procedures. J Gen Intern Med 2000;15:353-60. 